\title{
Uso de sistemas de comunicação suplementar e alternativa na Educação Infantil: percepção do professor
}

\author{
Munique Massaro* \\ Débora Deliberato**
}

Resumo

Os recursos de comunicação suplementar e alternativo podem inserir o aluno com deficiência e necessidades complexas de comunicação em diferentes atividades pedagógicas e ampliar as habilidades e as competências do professor no processo de ensino-aprendizagem. Assim, o objetivo da pesquisa foi identificar a percepção do professor a respeito do uso da comunicação suplementar e alternativa durante um programa de intervenção na Educação Infantil. Participaram uma classe especial da Educação Infantil que possui sete alunos com deficiência e necessidades complexas de comunicação, a professora e a pesquisadora. Para o desenvolvimento da pesquisa, aplicou-se um programa de comunicação alternativa. Ocorreram orientações sistemáticas à professora, a respeito de linguagem e comunicação. Em um processo colaborativo, foram selecionadas três canções infantis, conforme o planejamento pedagógico da professora e os recursos foram adaptados por meio de sistemas de comunicação suplementares e alternativos. Durante o programa de intervenção, também foram realizadas avaliações assistidas imediatamente após as atividades com a música. Os dados da pesquisa foram coletados por meio de gravação em áudio. Para análise dos dados, foi realizada análise de conteúdo, estabelecendo temas e subtemas. Os resultados indicaram que a professora identificou que sistemas de comunicação suplementares e alternativos podem favorecer as habilidades de expressão dos alunos com deficiência; que os sistemas de comunicação suplementares e alternativos podem ser utilizados por crianças na Educação Infantil; e que recursos adaptados por meio dos sistemas suplementares e alternativos de comunicação devem estar de acordo com as especificidades dos alunos.

Palavras-chave: Educação especial; Educação infantil; Sistemas de comunicação alternativos e aumentativos.

\footnotetext{
* Mestranda em Educação da Universidade Estadual Paulista Júlio de Mesquita Filho (Unesp), Brasil.

** Professora Doutora do Programa de Pós-Graduação em Educação. Departamento de Educação Especial - Universidade Estadual Paulista “Júlio de Mesquita Filho" (Unesp). Marília, São Paulo.
} 


\title{
Use of Augmentative and Alternative Communication Systems in Preschool: teacher perceptions
}

\begin{abstract}
Augmentative and Alternative Communication Resources have proven to be helpful in the insertion of students with disabilities and complex communication needs into a variety of pedagogical activities and expand the skills and competencies of the teacher in the teaching-learning. The objective of this research was to identify the perception of teachers regarding the use of augmentative and alternative communication during an intervention program in Preschool. Participants were a special class of Preschool students with disabilities and severe communication complexity, along with their teacher and the researcher. For the development of this research, a Alternative Communication Program was applied. The teacher was provided with systematic guidance concerning language and communication. In a collaborative process, three children's songs were selected according to the teacher's pedagogical planning and adapted resources through Augmentative and Alternative Communication Systems. During the intervention program, assisted evaluations also took place immediately after the activities with the music. The data were collected in audio recordings. For data analysis, content analysis was carried out resulting in the outlining of themes and subthemes. Results indicated that the teacher identified that Augmentative and Alternative Communication Systems can to facilitate expression abilities of students with disabilities; that Augmentative and Alternative Communication Systems can be used by children in Preschool; and that resources adapted through augmentative and alternative communication systems should be in accordance with the specificities of students.
\end{abstract}

Keywords: Special Education; Children's Education; Augmentative and alternative communication systems.

Introdução

A Educação Infantil, primeira etapa da Educação Básica, tem o objetivo de inserir a criança no mundo do conhecimento, na condição de ser alfabetizada e na leitura interpretativa de todas as coisas (ANGOTTI, 2010). 
Essa etapa da educação é um direito de todas as crianças, inclusive daquelas com deficiência. Por meio da tríade cuidar-educar-brincar elas poderão desenvolver as capacidades de apropriação e conhecimento das potencialidades corporais, afetivas, emocionais, estéticas e éticas (BRASIL, 1998a).

Entretanto, diante de alunos com deficiência na sala de aula, é possível identificar uma diversidade de tipos e graus de comprometimento. Essas diversidades envolvem dificuldades nas características motora, lingüística, cognitiva, sensório-perceptivas, sociais e emocionais. O desempenho funcional apresentado por crianças com deficiência pode estar comprometido em uma única área ou pode estar associado. O desempenho funcional comprometido pode dificultar ou impossibilitar determinadas ações da criança sobre o meio.

O Referencial Curricular Nacional para a Educação Infantil contemplou que o desempenho funcional da comunicação de crianças com deficiência pode afetar as habilidades expressivas por meio da fala, como as crianças com paralisia cerebral, com autismo, com deficiência auditiva. Dessa forma, recursos e procedimentos são necessários para favorecer a aquisição da linguagem por meio de sistemas suplementares e alternativos de comunicação (BRASIL, 1998b).

A área da comunicação suplementar e alternativa pode garantir a acessibilidade a diferentes sistemas de comunicação e melhorar a recepção, a compreensão e a expressão da linguagem de pessoas com deficiência e necessidades complexas de comunicação (DELIBERATO, 2005).

A comunicação suplementar e alternativa é multimodal e as crianças com necessidades complexas de comunicação devem ser estimuladas a usar todas as formas possíveis de comunicação para expressar suas necessidades básicas, vontades e desejos (ROMSKI, 2002; ROMSKI; SEVCIK, 2005).

Baseado nas discussões acerca da comunicação suplementar e alternativa como parte de um plano de intervenção com bebês e crianças pequenas, Romski e Sevcik (2005) constataram que serviços e suportes nessa área tem sido limitado, devido a uma série de mitos sobre o uso adequado da comunicação suplementar e alternativa. Foram verificados seis mitos: (1) a comunicação suplementar e alternativa deve ser o último recurso a ser empregado, quando todas as outras opções estiverem sido esgotadas; (2) a comunicação suplementar e alternativa dificulta o desenvolvimento da fala; (3) as crianças devem ter certo conjunto de competências para poder beneficiar da comunicação suplementar e alternativa; (4) a comunicação 
suplementar e alternativa são apenas para as crianças com cognição intacta; (5) as crianças tem que ter determinada idade para poder se beneficiar da comunicação suplementar e alternativa; (6) há uma representação hierárquica de símbolos a partir de objetos para a palavra escrita. Entretanto, nenhum desses mitos é sustentado pela literatura atual e há um reconhecimento crescente dos benefícios das intervenções de comunicação suplementar e alternativa com crianças pequenas.

O uso da comunicação suplementar e alternativa não interfere no desenvolvimento da fala, na verdade, esse recurso suporta tal desenvolvimento. Recursos e estratégias de comunicação suplementar e alternativa são um meio e podem definir o cenário para o desenvolvimento da linguagem e da comunicação durante os anos da Educação Infantil e primeiros anos do Ensino Fundamental, e ainda, podem colaborar para a progressão do desenvolvimento global da criança. Logo, nunca será cedo demais para incorporar a comunicação suplementar e alternativa na intervenção com crianças com uma deficiência de comunicação significativa (ROMSKI; SEVCIK, 2005).

Os recursos de comunicação suplementar e alternativa podem colaborar para o processo de aquisição e desenvolvimento da linguagem, para o desenvolvimento da competência comunicativa e também podem inserir o aluno com deficiência e necessidades complexas de comunicação em diferentes atividades pedagógicas, colaborando assim, para o processo de ensino e aprendizagem. Além disso, a literatura tem discutido que a música adaptada por meio de sistemas de comunicação suplementares e alternativos pode ser um recurso importante para trabalhar diversos conteúdos acadêmicos (SAMESHIMA, 2011; MASSARO; DELIBERATO; RODRIGUES, 2010; DELIBERATO et al., 2008; DELIBERATO; PAURA; NETA, 2007; PAURA; DELIBERATO, 2007).

$\mathrm{Na}$ escola, o educador deve criar ambientes sociais e significativos que apóiem a aquisição de sistemas alternativos de comunicação, pois esses ambientes não se constituem naturalmente. A comunicação suplementar e alternativa não é uma forma natural de comunicação, assim, o desenvolvimento da linguagem demanda um processo de construção e planejamento (VON TETZCHNER et al., 2005; VON TETZCHNER, 2009; DOWNING, 2009).

Além disso, os recursos devem estar de acordo com os objetivos propostos pelo professor e adequados à especificidade de cada aluno, considerando as possibilidades cognitivas, visuais e motoras de todos os usuários (DELIBERATO, 2005). 
Nesse contexto, pode-se evidenciar o desafio do professor de Educação Infantil para trabalhar com a comunicação suplementar e alternativa em sala de aula e desenvolver as competências necessárias lingüística, operacional, social e estratégica - para o uso dessa modalidade de comunicação (LIGHT, 2003).

A capacitação de professores frente à política de inclusão se faz necessária e é de extrema importância que os pais, professores e assistentes de sala recebam orientações sobre o sistema de comunicação alternativa que está sendo usado pelo aluno, bem como acerca do ensino de novas estratégias para ampliar a comunicação e a interação (SAMESHIMA, 2011).

No estudo de Nunes et al. (2009) foi possível evidenciar que quando o professor tem pouco conhecimento a respeito dos sistemas e recursos de comunicação alternativa, ele encontrará dificuldade de manusear e elaborar estratégias que facilitem o processo comunicativo e, consequentemente, o uso nas diversas atividades. O resultado da pesquisa indicou a participação inexpressiva da professora no uso de recursos de comunicação alternativa em sala de aula frente à falta de conhecimento do uso dos sistemas.

Em outra pesquisa realizada com capacitação de professores, Manzini e colaboradores (2009) tiveram o objetivo de inserir os professores de alunos com deficiência e necessidades complexas de comunicação na confecção de atividades pedagógicas por meio do uso de recursos de comunicação suplementar e alternativa. Os resultados indicaram que os professores mostraram conscientização da importância de adaptações com recursos de comunicação alternativa. Os professores participaram de reuniões semanais, para identificar os conteúdos do planejamento pedagógico e selecionar os conteúdos para as adaptações e adequações de materiais, por meio do recurso de comunicação suplementar e alternativa. Durante os encontros foi feita a adaptação de parlendas, poesias, textos e outras atividades pedagógicas. A capacitação dos professores auxiliou na identificação e na adaptação das atividades e na compreensão da importância dos recursos de comunicação suplementar e alternativa no processo de ensino e aprendizagem dos alunos com deficiência.

Além desses aspectos pedagógicos, o professor é responsável pela qualidade da relação ensino-aprendizagem, que é interpessoal e não apenas didático. Dessa maneira, o educador precisa rever constantemente seus hábitos e crenças enraizados, pois suas ações têm como base uma concepção que foi desenvolvida dentro do processo histórico. A concepção que o educador infantil tem a respeito da deficiência, por exemplo, direciona a prática e determina as atitudes em relação aos alunos com deficiência (OMOTE, 2000, 2001). 
A implementação de estratégias de ensino inovadoras na área da Educação Especial também foi relacionada com as crenças educacionais dos professores. Pesquisas educacionais apontaram que conhecimentos teóricos e habilidades por si só não são suficientes para um ensino eficaz. A ação eficaz depende da opinião pessoal do professor (SOTO, 1997).

Kent-Walsh e Light (2003) realizaram uma pesquisa para investigar as experiências de 11 professores do Ensino regular que tinham alunos que usavam comunicação suplementar e alternativa em suas classes. As pesquisadoras identificaram, por meio de entrevistas, que os professores encontravam barreiras relacionadas a si mesmo para a inclusão de alunos que usavam a comunicação suplementar e alternativa, como a própria formação e competência limitada, mas também as atitudes negativas a esse processo.

Soto (1997) desenvolveu uma pesquisa cujo objetivo foi analisar e descrever as crenças de professores de educação especial no estado de Indiana para o uso de recursos de comunicação suplementar e alternativa por alunos com deficiências severas de comunicação. Foi utilizado um grupo focal para a elaboração de um questionário e duas versões finais desse instrumento foram respondidas por 187 professores que trabalhavam com alunos com deficiências graves ou múltiplas. Os resultados indicaram que as percepções dos professores acerca das habilidades dos seus alunos para aprender a se comunicar de modo mais eficaz foi o fator mais importante para influenciar a vontade dos professores de utilizar recursos de comunicação suplementar e alternativa em sala de aula. Esse mesmo fator foi diretamente influenciado pela percepção dos professores a respeito de suas próprias habilidades e responsabilidades e das responsabilidades do fonoaudiólogo de utilizar recursos de comunicação suplementar e alternativa. Ou seja, os professores que acreditam que podem influenciar o desempenho de seus alunos, na medida em que tem melhores percepções das habilidades de seus alunos para aprender e, portanto, tem maiores expectativas em relação ao desempenho de seus alunos.

Sendo assim, a educação de crianças com deficiência na Educação Infantil, seja em classes regulares ou em classes especiais, deve ser intencionalmente organizada para que os conteúdos pedagógicos sejam adequados à diversidade de cada criança. Ademais, o professor, além de estabelecer interações sociais significativas, deve constantemente refletir a respeito da sua prática pedagógica, para que as estratégias de ensino, equipamentos e recursos utilizados atendam as necessidades dos alunos, garantindo assim, condições de acessibilidade. 


\section{Objetivo}

Identificar a percepção do professor a respeito do uso da comunicação suplementar e alternativa durante um programa de intervenção na Educação Infantil.

\section{Material e Método}

Cumprindo às recomendações da Resolução 196/96 do Conselho Nacional de Saúde, a pesquisa foi aprovada por um Comitê de Ética e aprovado sob o protocolo $n^{\circ} 1000 / 2010$. Além disso, a professora e os pais dos alunos selecionados assinaram o Termo de Consentimento Livre e Informado para autorização da realização do estudo.

Participaram da pesquisa uma classe especial da Educação Infantil que possui sete alunos com deficiência e necessidades complexas de comunicação, a professora e a pesquisadora. A coleta de dados foi realizada no período de maio a dezembro de 2010.

A professora tinha 46 anos e foi formada em Pedagogia com Habilitação em Deficiência Auditiva. Formou-se no ano de 1985 e não participou de nenhum outro curso em Educação Especial após sua graduação. Ela já teve contato com alunos com deficiência (alunos com síndrome de down) incluídos no Ensino Regular durante sua trajetória profissional.

A pesquisadora tinha 26 anos e foi formada em Pedagogia com Habilitação em Deficiência Física. Já teve experiência com alunos com deficiência e necessidades complexas de comunicação durante os anos de 2006 à 2009 com o desenvolvimento de projetos de extensão universitária e iniciação científica durante a sua graduação.

Em relação à caraterização dos alunos, segue um quadro. O nome das crianças é fictício. Esses dados foram obtidos por meio do Protocolo para avaliação das habilidades comunicativas de alunos não-falantes em situação escolar (PAULA, 2007). 
Quadro 1 - Caracterização dos alunos participantes

\begin{tabular}{|c|c|c|c|}
\hline Nome & Idade & Diagnóstico & $\begin{array}{l}\text { Modalidades de } \\
\text { Comunicação }\end{array}$ \\
\hline Amanda & 3 anos & $\begin{array}{l}\text { Síndrome de } \\
\text { West }\end{array}$ & $\begin{array}{l}\text { Não verbal: choro, risada, } \\
\text { expressão facial, olhar } \\
\text { direcionado, linguagem } \\
\text { corporal (intenção de pegar } \\
\text { objetos). }\end{array}$ \\
\hline Marcela & 5 anos & $\begin{array}{l}\text { Paralisia } \\
\text { Cerebral }\end{array}$ & $\begin{array}{l}\text { Não verbal: choro, } \\
\text { risada, expressão facial, } \\
\text { vocalização, olhar } \\
\text { direcionado, linguagem } \\
\text { corporal (balançar o corpo, } \\
\text { bater palmas, morder a mão, } \\
\text { empurrar objetos). }\end{array}$ \\
\hline Alan & 4 anos & $\begin{array}{l}\text { Síndrome do } \\
\text { Noonan }\end{array}$ & $\begin{array}{l}\text { Não verbal: choro, } \\
\text { risada, expressão facial, } \\
\text { vocalização, olhar } \\
\text { direcionado, linguagem } \\
\text { corporal (intenção de pegar } \\
\text { objetos, recusar objetos, } \\
\text { morder). }\end{array}$ \\
\hline Bruno & 3 anos & $\begin{array}{l}\text { Hidrocefalia } \\
\text { e Paralisia } \\
\text { Cerebral }\end{array}$ & $\begin{array}{l}\text { Não verbal: choro, } \\
\text { risada, expressão facial, } \\
\text { vocalização, gesto (jóia), } \\
\text { linguagem corporal (recusar } \\
\text { objetos). }\end{array}$ \\
\hline Davis & 6 anos & $\begin{array}{l}\text { Síndrome de } \\
\text { Dandy Walker }\end{array}$ & $\begin{array}{l}\text { Verbal e não verbal: fala } \\
\text { monossilábica, choro, risada, } \\
\text { expressão facial, olhar } \\
\text { direcionado, vocalização, } \\
\text { gestos indicativos e } \\
\text { representativos, linguagem } \\
\text { corporal, apontar. }\end{array}$ \\
\hline Giovany & 3 anos & $\begin{array}{l}\text { Hidrocefalia, } \\
\text { Paralisia } \\
\text { Cerebral e } \\
\text { Deficiência } \\
\text { Visual }\end{array}$ & $\begin{array}{l}\text { Não verbal: choro, } \\
\text { risada, expressão facial, } \\
\text { vocalização. }\end{array}$ \\
\hline Gabriel & 6 anos & $\begin{array}{l}\text { Paralisia } \\
\text { Cerebral e } \\
\text { Deficiência } \\
\text { Visual }\end{array}$ & $\begin{array}{l}\text { Não verbal: choro, risada, } \\
\text { expressão facial, linguagem } \\
\text { corporal (balançar o corpo). }\end{array}$ \\
\hline
\end{tabular}

Fonte: produção do próprio autor. 
Para o desenvolvimento da pesquisa, aplicou-se um programa de comunicação alternativa, constituído de três etapas (DELIBERATO, 2009, 2011). Na primeira etapa ocorreram orientações sistemáticas a respeito de linguagem e comunicação, apresentação dos sistemas de comunicação suplementares e alternativos e o vínculo dos sistemas com as questões de comunicação e a aprendizagem da leitura e escrita à professora; foi identificado o currículo da escola e obteve conhecimento do planejamento pedagógico da sala de aula. Na segunda etapa foram identificadas as habilidades dos alunos e a rotina da escola por meio de entrevistas com a professora. O instrumento de pesquisa utilizado nessa etapa foi o Protocolo para avaliação das habilidades comunicativas de alunos não-falantes em situação escolar (PAULA, 2007). A terceira etapa consistiu da elaboração e adaptação de recursos por meio dos sistemas de comunicação suplementares e alternativos e na aplicação da intervenção.

Nessa última etapa, foram selecionadas três canções infantis, conforme o planejamento pedagógico da professora, para serem trabalhadas com os alunos. As músicas selecionadas foram: "O sapo não lava o pé", "Cinco patinhos" e "O elefante queria voar". Cada música selecionada foi trabalhada em cinco encontros, uma vez na semana. Após o planejamento das atividades, houve a adaptação das letras das músicas por meio da confecção das figuras do Picture Communication Symbols (MAYER-JONHSON, 2004) e confecção dos recursos de baixa tecnologia - pranchas frasais e pranchas temáticas - para serem utilizados nas situações de ensino-aprendizagem. Além disso, selecionaram-se miniaturas e objetos concretos também para serem utilizados nas situações de ensino-aprendizagem. Esse trabalho foi desenvolvido juntamente com a professora.

Assim, ocorreu o desenvolvimento das atividades pedagógicas em um trabalho colaborativo, no qual a pesquisadora e a professora estiveram envolvidas; e o uso dos recursos nas atividades planejadas com a música. A pesquisadora atuou junto com a professora em todas as atividades do programa de comunicação alternativa na sala de aula durante quatro meses.

Durante o desenvolvimento das atividades pedagógicas ao longo do semestre, também foram realizadas avaliações assistidas, imediatamente após ocorrida a atividade da semana. O instrumento de pesquisa utilizado durante essas avaliações foi o Protocolo para Avaliação Processual que foi elaborado pela pesquisadora.

Nessas avaliações assistidas, pesquisadora e professora discutiram em conjunto os pontos positivos e os pontos negativos do encontro realizado e as sugestões para o próximo encontro. Essas discussões abrangeram cinco 
temas: recursos, atividades, mediação, alunos e vínculo com o planejamento. As 15 avaliações foram registradas em aparelho gravador de áudio.

Após a coleta de dados, as avaliações assistidas foram transcritas na íntegra pela pesquisadora, seguindo as normas estabelecidas por Marcuschi (1986) e demais símbolos determinados para facilitar a padronização das informações, tais como: /.../ interferência ambiental de pessoas ou demais recursos; \{\} pausa do entrevistado; E entrevistador/pesquisador; $P$ professor; A aluno. Em seguida, as avaliações foram ouvidas novamente e adequadas, quando necessário.

Para a análise dos dados, foi realizada análise de conteúdo, estabelecendo temas e subtemas, que foram submetidos e delineados como representativos pela indicação de dois juízes da área de Educação Especial (BARDIN, 2000).

Os temas e subtemas estabelecidos foram:

\section{Alunos - atividades}

Foram incluídas nesse tema as atividades do programa de intervenção desenvolvidas com o grupo de alunos e individualmente.

Habilidades expressivas: foram considerados todos os comportamentos executados com intencionalidade pelos alunos com deficiência, durante as atividades, quer por meio de habilidades verbais e não-verbais.

Habilidades motoras: nesse subtema foram contempladas as informações a respeito do uso de habilidades para produzir movimentos, posições, orientações com mão e corpo usadas pelos alunos com deficiência nas atividades.

\section{Material pedagógico}

Esse tema se refere aos sistemas de comunicação suplementar e alternativa adaptados para a realização da atividade pedagógica durante o programa de intervenção. 
Sistemas: foi considerado sistema o signo lingüístico (significado/ significante) da área da comunicação alternativa possível de representar um determinado conteúdo para os alunos com deficiência. Foram considerados sistemas de representação: símbolos gráficos Picture Communication Symbols (PCS), objetos reais e miniaturas.

\section{Resultados e discussão}

Os resultados e discussão serão apresentados a partir dos temas e subtemas de análise de conteúdo estabelecidos das avaliações assistidas realizadas entre professora e pesquisadora. De acordo com o objetivo do artigo, os resultados serão focados na percepção da professora.

\section{Alunos - habilidades expressivas}

Identificar as habilidades expressivas de alunos com necessidades complexas de comunicação durante as atividades é importante para o estabelecimento de estratégias que ampliem as condições de comunicação e para adaptar recursos de comunicação suplementar e alternativa às necessidades de cada aluno.

Para expressar suas necessidades básicas, vontade e desejos, crianças com necessidades complexas de comunicação devem ser estimuladas a usar todas as formas possíveis de comunicação (ROMSKI, 2002; ROMSKI; SEVCIK, 2005).

Nesse sentido, observa-se nos exemplos a seguir, que a professora identificou as habilidades expressivas dos alunos durante o programa de intervenção frente ao material pedagógico e aos sistemas de comunicação suplementar e alternativa.

$P$ : então assim, eles/ eu acho que eles tem um nível deles de limitação e de condição pra participar ou não e A2 ela ela tenta eu perce/, eu eu SINTO assim, eu observo em TODAS as coisas que eu vou fazer com ela, que ela ela quer interagir

E: $\operatorname{sim}$

$\mathrm{P}$ : e dentro das possibilidades dela, que nem ela ficou ali, quietinha, sentada, olhava

$\mathrm{E}$ : e ela tentava pegar na/ movimenta o braço com a intenção 


$$
\begin{aligned}
& \text { P: na direção é } \\
& \text { E: é } \\
& \text { P: e quando ela ta assim sem fazer alguma atividade, } \\
& \text { esperando alguma coisa, ela brinca com a própria } \\
& \text { mãozinha, e que não foi o caso hoje (...) } \\
& \text { P: e o A1 também aproveitou muito a FALA se viu que ele } \\
& \text { cantou alguns trechos } \\
& \text { E: é } \\
& \text { P: sapo e pé e chulé e tudo eu achei ótimo (...) }
\end{aligned}
$$

Evidenciou-se que o uso da comunicação suplementar e alternativa em atividades com músicas adaptadas não constituiu em fator de inibição da fala, ao contrário, esse recurso favoreceu-a (ROMSKI; SEVCIK, 2005).

Além disso, a professora e a pesquisadora relataram que os alunos apresentaram intenção comunicativa durante as atividades do programa de intervenção, por meio de sinais verbais e não verbais.

\section{Alunos - habilidades motoras}

Para a obtenção da competência comunicativa, a interação do conhecimento e habilidades entre os quatros domínios - lingüístico, operacional, social e estratégico - são necessários (LIGHT, 2003).

As habilidades operacionais são necessárias para acessar ou produzir os símbolos de comunicação suplementar e alternativa, ou seja, referem-se às habilidades para a produção técnica e operação dos sistemas de baixa ou alta tecnologia. Nelas incluem as habilidades para produzir movimentos, posições, orientações, formas de mão e de corpo, por isso dependem das capacidades motora, cognitiva, lingüística e sensório perceptiva dos usuários (LIGHT, 2003).

Nos exemplos que seguem, pode-se evidenciar que a professora identificou as habilidades motoras dos alunos para operação dos sistemas de comunicação suplementar e alternativa. No entanto, a professora também relatou que os alunos têm graves comprometimentos na capacidade motora, podendo dificultar assim, o desenvolvimento das habilidades operacionais.

P: eu achei excelente... achei que foi muito bom... inclusive para as crianças manusearem as figuras você não achou"

E: hã hãm

$P$ : achei que foi super legal, as crianças manusearam 
Uso de sistemas de comunicação suplementar e alternativa na Educação Infantil: percepção do professor

E: é dá pra elas pegarem e ver a figura né"

$P$ : e vê a figura, porque na outra eles poderiam até pegar, mas não tinha aquela a a figura não seria tão nítida

$\mathrm{E}:$ hã hãm (...)

P: (...) mas esses aqui você vê né" que eles mal abrem a mãozinha, mas achei tudo válido né" gostei, a gente combinou, fomos foi planejado, não tem como (...)

$P$ : hu hum não porque é um é um RITUAL, porque CADA um é um posicionamento diferente, cada um você tem um você senta no colo, o outro você põe com a prancheta na frente, o outro deitado com a prancheta, o outro é no carrinho, entendeu" o A1 e a A3 na mesinha a A2 deitada no meu colo eu tenho que colocar na frente dela e depois é tirar e pegar a mãozinha e aí eu explico tudo de novo e aí eu ponho a mãozinha pra não judiar sabe então é uma coisa demoradíssima (...)

O exemplo reforça a necessidade de identificar o tipo e o tamanho de materiais que os alunos conseguem manusear, suas habilidades motoras e diversas outras habilidades e adaptações que necessitam. Sendo assim é fundamental o professor planejar eficientemente as estratégias de ensino para selecionar, adequar e implementar os recursos de comunicação suplementar e alternativa (DELIBERATO, 2009; ROCHA; DELIBERATO, 2012).

\section{Material pedagógico - sistemas}

O desenvolvimento da linguagem envolve vários processos paralelos e integrados, como a análise perceptiva da estimulação sensorial, a exploração do ambiente físico e social, e as interações com os cuidadores e outras pessoas significativas que direcionam a entrada no mundo sóciocultural (VON TETZCHNER et al., 2005).

Assim, sistemas de comunicação suplementares e alternativos podem funcionar como um sistema de representação alternativo para que os alunos com deficiência e necessidades complexas de comunicação participem ativamente das diversas práticas sociais, já que elas têm ausência de fala ou uma fala ininteligível. Logo, por meio do sistema de representação a criança poderá não só aprender as palavras, mas seus significados culturais. Ela poderá comunicar idéias em diferentes situações, aumentar suas vivências, enfim, construir um conhecimento de natureza conceitual.

Os exemplos que seguem, apresentam o relato da professora a respeito da utilização de diversos sistemas de comunicação suplementares e alternativos necessários para atender as especificidades dos alunos. 
$\mathrm{P}$ : deu continuidade e e assim você concretizou a lagoa, dentro do que a gente consegue, dos bichinhos né" não tem mais o que fazer além disso porque trabalhar com figuras e gravuras com eles só é muito abstrato

$\mathrm{E}$ : sim é não dá só figura não dá (...)

P: o que eu achei é eu acho eu eu achei bacana né" concordei eu faria mesmo igual você fez colocando o animal, o objeto e a figura e tudo mais eu acho que é isso que tem que ser feito mesmo (...)

Observa-se que a professora, apesar de relatar que o trabalho somente com as figuras do Picture Communication Symbols é abstrato para seus alunos, considerou que os sistemas utilizados na comunicação suplementar e alternativa envolvem diferentes elementos com complexidades distintas. O uso dos símbolos gráficos pode ser inserido de acordo com o momento do desenvolvimento de cada criança e poderia ser o mediador na aprendizagem da leitura e da escrita (ROMSKI; SEVCIK, 2005; DELIBERATO, 2011).

Nos próximos exemplos, a professora identificou a necessidade dos recursos de comunicação suplementar e alternativa estarem de acordo com as especificidades dos alunos

$$
\begin{aligned}
& \text { P: achei bacana achei que os recursos/ a figura E o } \\
& \text { objeto foram MUlto parecidos } \\
& \text { E: hã hãm } \\
& \text { P: achei que foi muito assim dá pra identificar bem } \\
& \text { E: bem né" e entre a figura e o objeto né" } \\
& \text { P: hu hum é (...) } \\
& \text { P: ah os recursos foram ótimos ((sorriso)) adorei o peixe, } \\
& \text { o jacaré de um tamanho razoalmente grande e assim é } \\
& \text { (...) você trouxe o o os bichinhos maiores, um tamanho } \\
& \text { ideal pra que eles possam pegar porque não podem ser } \\
& \text { uma coisa enorme pra PEGAR, pra OLHAR quanto maior } \\
& \text { melhor, mas pegar, pra manusear tem que ser uma coisa, } \\
& \text { de um tamanho que não seja miudinho, mas alguma } \\
& \text { coisa } \\
& \text { E: dá pra pegar e ver ao mesmo tempo (...) }
\end{aligned}
$$

Em situação escolar, os recursos devem estar de acordo com os objetivos propostos pelo professor e adequados à especificidade de cada aluno, considerando as possibilidades cognitivas, visuais e motoras de todos usuários (DELIBERATO, 2005).

A adequação dos recursos tem uma relação direta com o currículo escolar, eles são determinados pelos objetivos da intervenção de ensino, como são meio para que os objetivos se realizem (ARAÚJO, MANZINI, 2001). 
Portanto, conhecer todas as adaptações e recursos que os alunos necessitam para realizar atividades dentro e fora da sala de aula e identificar as habilidades e limitações de cada aluno são cuidados necessários para a implementação de recursos alternativos e suplementares de comunicação.

\section{Conclusão}

A escola, principalmente a Educação Infantil, é o local de maior possibilidade do ensino das linguagens alternativas e para que seja possível a constituição da competência linguística de crianças com deficiência e necessidades complexas de comunicação (VON TETZCHNER, 2009).

Esta pesquisa, cujo objetivo foi identificar a percepção do professor a respeito do uso da comunicação suplementar e alternativa durante um programa de intervenção na Educação Infantil, demonstrou que a professora percebe que os sistemas de comunicação suplementares e alternativos podem ser utilizados por crianças pequenas na Educação Infantil e podem favorecer a expressão dos alunos, corroborando com as afirmações de Romski e Sevcik (2005) de que recursos e estratégias de comunicação suplementar e alternativa são um meio e podem definir o cenário para o desenvolvimento da linguagem e da comunicação durante os anos da Educação Infantil e primeiros anos do Ensino Fundamental.

De acordo com Von Tetzchner e colaboradores (2005) o desenvolvimento de ações por meio dos sistemas suplementares e alternativos de comunicação na escola deve ser programado e há necessidade de competência no uso desses sistemas. No presente trabalho, a pesquisadora já tinha experiência e contato com diferentes ações por meio da área em situações escolares e a professora atuou, em um trabalho colaborativo com a pesquisadora, no desenvolvimento das atividades pedagógicas e no uso dos recursos nas atividades planejadas com a música. Esse envolvimento do professor possibilitou assim, sua formação continuada.

A capacitação de professores frente à política de inclusão se faz necessária e é de extrema importância que os pais, professores e assistentes de sala recebam orientações sobre o sistema de comunicação alternativa que está sendo usado pelo aluno, bem como acerca do ensino de novas estratégias para ampliar a comunicação e a interação desses alunos (SAMESHIMA, 2011).

Pode-se concluir também que a professora percebeu que os recursos de comunicação suplementar e alternativa devem estar de acordo com as 
especificidadesdosalunos; eainda, pode-severificarqueaprofessoraidentificou as habilidades expressivas e motoras dos alunos no uso da comunicação suplementar e alternativa durante o programa de intervenção desenvolvido.

Light (2003) afirmou que para a obtenção da competência comunicativa e para garantir o seu sucesso, a interação do conhecimento e habilidades entre os quatros domínios - linguístico, operacional, social e estratégico - são necessários. Portanto, é importante desenvolver as habilidades operacionais dos alunos, bem como as outras habilidades, para que seja garantido o direito das crianças com deficiência à comunicação e ao desenvolvimento da linguagem.

Enfim, há necessidades de mais estudos que direcione ações a fim de construir um trabalho colaborativo entre professores e pesquisadores, para que as estratégias e o uso dos sistemas suplementares e alternativos de comunicação no contexto escolar, mas especificamente na Educação Infantil, sejam aprimorados.

\section{Referências}

ANGOTTI, M. Educação infantil: para que, para quem e por quê. In: ANGOTTI, M. (Org.). Educação infantil: para que, para quem e por quê? 3. ed. Campinas: Alínea, 2010. p. 15-32.

ARAÚJO, R. de C. T.; MANZINI, E. J. Recursos de ensino na escolarização do aluno com deficiência física. In: MANZINI, E. J. Linguagem, cognição e ensino do aluno com deficiência. Marília: Unesp-Marília, 2001. p. 1-11.

BARDIN, L. Análise de conteúdo. Lisboa: 70, 2000.

BRASIL. Ministério da Educação e do Desporto. Secretaria de Educação Fundamental. Referencial curricular nacional para a educação infantil. Brasília, DF: MEC; SEF, v.1, 1998a. 103 p.

- Ministério da Educação e do Desporto. Secretaria de Educação Fundamental. Referencial curricular nacional para a educação infantil. Brasília, DF: MEC; SEF, v. 3, 1998b. 269 p.

DELIBERATO, D. Comunicação alternativa e educação especial: ações inclusivas para crianças e jovens com deficiência In: Transtornos de aprendizagem 2: da análise laboratorial e da reabilitação clínica para as políticas públicas de prevenção pela via da educação. 1. ed. São Paulo: Memnon Científicas, 2011. p. 181-186. 
. Comunicação alternativa na escola: habilidades comunicativas e o ensino da leitura e escrita. In: DELIBERATO, D.; GONÇALVES, M. J.; MACEDO, E. C. (Org.). Comunicação alternativa: teoria, prática, tecnologias e pesquisa. São Paulo: Memnon Edições Científicas, 2009. p. 235-243.

Seleção, adequação e implementação de recursos alternativos e/ ou suplementares de comunicação. In: PINHO, S.Z. de.; SAGLIETTI, J. R. C. (Orgs.). Núcleo de ensino. Universidade Estadual Paulista: Publicações, v. 11, 2005. p. 505-519.

DELIBERATO, D.; PAURA, A. C.; MASSARO, M.; RODRIGUES, V. Comunicação suplementar e ou alternativa no contexto da música: recursos e procedimentos para favorecer o processo de inclusão de alunos com deficiência. In: PINHO, S. Z.; SAGLIETTI, J. R. C. (Orgs.). Livro eletrônico dos Núcleos de ensino. São Paulo: Cultura Acadêmica, v. 1, 2008. p. 890901.

DELIBERATO, D.; PAURA, A. C.; NETA, D. P. Comunicação suplementar e alternativa no contexto da música. In: NUNES, L. R. O. P.; PELOSI, M. B.; GOMES, M. R. (Orgs.). Um retrato da comunicação alternativa no Brasil. Rio de Janeiro: 4 Pontos Estúdio Gráfico e Papéis, v. 1, 2007. p. 77-81.

DOWNING, J. E. Assessment of early communication skills. In: SOTO, G.; ZANGARI, C. Practically speaking: language, literacy and academic development for students with AAC needs. Baltimore: Paul H. Brookes, 2009. p. 27-46.

KENT-WALSH, J., \& LIGHT, J. General education teachers" experiences with inclusion of students who use augmentative and alternative communication. Augmentative and Alternative Communication, v. 19, p. 104-124, jun. 2003.

LIGHT, J. C. Development of communicative competence by individuals who use AAC. In: LIGHT, J. C.; BEUKELMAN, D. R.; REICHLE, J. Communicative competence for individuals who use AAC. Baltimore: Paul H. Brookes, 2003. p. 3-38.

MANZINI, M. G. et al. Adaptação das atividades escolares por meio da comunicação suplementar e alternativa. In: III CONGRESSO BRASILEIRO DE COMUNICAÇÃO ALTERNATIVA, 2009, São Paulo. Anais de Resumos e Trabalhos Completos. São Paulo: ABPEE, 2009. v. 1. CD-ROM. 
MARCUSCHI, L. A. Análise da conversação. São Paulo: Ática, 1986. 94 p. (Série Princípios).

MASSARO, M.; DELIBERATO, D.; RODRIGUES, V. Augmentative and alternative communication resources in song interpreting and storytelling activities for disabled students. In: BIENNIAL CONFERENCE OF THE INTERNATIONAL SOCIETY FOR AUGMENTATIVE AND ALTERNATIVE COMMUNICATION, 14th., 2010, Barcelona. Main Conference Program. Canadá: ISAAC, 2010. v. 1. p. 1214-1217.

MAYER-JONHSON, R. The picture communication symbols P. C. S. Software Boardmaker. Porto Alegre: Clik Tecnologia Assistiva, 2004.

NUNES, L. R. O. P. et al. O emprego de tipos diversos de pranchas de comunicação alternativa em sala de aula. In: MANZINI, E.J. et al. Linguagem e comunicação alternativa. Londrina: ABPEE, n. 2, p. 9-18, 2009.

OMOTE, S. Classes Especiais: comentários à margem do texto de Torezan \& Caiado. Revista Brasileira de Educação Especial. Marília, v. 6, n. 1, p. 43-64, 2000.

A concepção de deficiência e a formação do profissional em educação especial. In: MARQUEZINE, M. C.; ALMEIDA, M. A.; TANAKA, E. D. O. (Orgs.). Perspectivas multidisciplinares em educação especial II. Londrina: UEL, 2001. p. 45-52.

PAULA, R. de. Desenvolvimento de um protocolo para avaliação de habilidades comunicativas de alunos não-falantes em ambiente escolar. 2007. 148 f. Dissertação (Mestrado em Educação)- Faculdade de Filosofia e Ciências, Universidade Estadual Paulista, Marília, 2007.

PAURA, A. C.; DELIBERATO, D. Comunicação Alternativa e/ou Suplementar como recurso de apoio no ensino do conteúdo pedagógico de criança deficiente incluída. In: II CONGRESSO BRASILEIRO DE COMUNICAÇÃO ALTERNATIVA, 2007, Campinas. Anais de Resumos e Trabalhos Completos. Campinas: Unicamp, 2007. v. 1. p. 1-8. CD-ROM.

ROCHA, A. N. D. C.; DELIBERATO, D. Tecnologia assistiva para a criança com paralisia cerebral na escola: identificação das necessidades. Revista Brasileira de Educação Especial. Marília, v. 18, p. 71 - 92, 2012.

ROMSKI, M. A. et al. A continuum of AAC language intervention strategies for beginning communicators. In: REICHLE, J.; BEUKELMAN, D. R.; LIGHT, J. C. 
Exemplary practices for beginning communicators: implications for AAC. Baltimore: Paul H. Brookes, 2002.

ROMSKI, M. A.; SEVCIK, R. A. Augmentative Communication and Early Intervention: Myths and Realities. Infants \& Young Children, v. 18, n. 3, p. 174-185, jul./set. 2005.

SAMESHIMA, F. S. Capacitação de professores no contexto de sistemas de comunicação suplementar e alternativa, 2011. 173 f. Tese (Doutorado em Educação) - Faculdade de Filosofia e Ciências, Universidade Estadual Paulista, Marília, 2011.

SOTO, G. Special Education Teacher Attitudes toward AAC: preliminary survey. Augmentative and Alternative Communication, v. 13, n. 3, p. 186197, set. 1997.

VON TETZCHNER, S. et al. Inclusão de crianças em educação pré-escolar regular utilizando comunicação suplementar e alternativa. Revista Brasileira de Educação Especial. Marília, v. 11, n. 2, p. 151-184, mai./ago. 2005.

VON TETZCHNER, S. Suporte ao desenvolvimento da comunicação suplementar alternativa. In: DELIBERATO, D.; GONÇALVES, M. J.; MACEDO, E. C. (Org.). Comunicação alternativa: teoria, prática, tecnologias e pesquisa. São Paulo: Memnon Edição Científicas, 2009. p.14-27.

Correspondência

Munique Massaro - Rua Emílio Palma, n. 280C, Jd. Progresso. CEP 17513-030 - Marília - São Paulo.

E-mail: munique_massaro@yahoo.com.br - delibera@marilia.unesp.br

Recebido em 23 de abril de 2012

Aprovado em 04 de fevereiro de 2013 
